\title{
Os saberes psi no discurso da Educação Matemática: repensando as práticas de memorização
}

\section{"Psi" knowledge in the discourse of Mathematics Education: rethinking the practices of memorization}

\author{
Alice Stephanie Tapia Sartori \\ Claudia Glavam Duarte
} \begin{abstract}
prévio do aluno"; "é preciso trabalhar com as emoções em sala de aula, substituindo o medo pelo prazer de aprender"; "é necessário desenvolver os diversos tipos de memória", dentre outros. O material da pesquisa compreende 26 exemplares da Revista Nova Escola, analisados a partir da análise do discurso em uma perspectiva foucaultiana.
\end{abstract}

Resumo: Este artigo tem como objetivo problematizar a memorização no ensino de Matemática a partir dos discursos advindos dos saberes psi, como é o caso do construtivismo. Especialmente 0 enunciado que afirma que o aluno é construtor do conhecimento e que o professor não deve oferecer algo pronto para que o estudante apenas memorize, adquiriu força e mobilizou novas estratégias, como é o caso do uso de materiais concretos no ensino de Matemática. Assim, alguns enunciados são produzidos ou reforçados por estas teorias: "deve-se considerar o conhecimento

Palavras-chave: Memorização. Saberes psi. Construtivismo. Educação Matemática.

Abstract: This article aims to problematize memorization in the teaching of Mathematics from the discourses arising from "psi" knowledge, as is the case with constructivism. Especially the statement that the student is a builder of knowledge and that the teacher should not offer something ready for the student to just memorize, did acquire strength and mobilized new strategies, such as the use of concrete materials in the teaching of Mathematics. Thus, some statements are produced or reinforced by these theories: "the student's prior knowledge must be considered"; "It is necessary to work with emotions in the classroom, replacing fear with the pleasure of learning"; "It is necessary to develop the different types of memory", among others. The research material comprises 26 copies of the Revista Nova Escola, studied from the analysis of the discourse in a Foucauldian perspective.

Keywords: Memorization. Psi knowledge. Constructivism. Mathematics Education.

\section{Introdução}

Este texto aborda uma problematização a respeito da memorização no ensino de Matemática, que de modo mais abrangente foi desenvolvida em uma tese de doutorado (SARTORI, 2019) a partir de uma perspectiva filosófica. Michel Foucault, nosso filósofo
Alice Stephanie Tapia Sartori Doutora em Educação Cientifica e Tecnológica. Professora da Universidade Federal do Rio Grande do Sul (UFRGS), campus Litoral Norte. Rio Grande do Sul,

$$
\text { Brasil. }
$$

iD orcid.org/0000-0002-0442-6645 \alice.stephanie.ts@gmail.com

Claudia Glavam Duarte Doutora em Educação. Professora do Programa de Pós Graduação de Educação em Ciências da Universidade Federal do Rio Grande do Sul (UFRGS). Professora Colaboradora do Programa de PósGraduação em Educação Científica e Tecnológica da Universidade Federal de Santa Catarina (UFSC). Rio Grande do Sul, Brasil. D orcid.org/0000-0002-8608-5855 $\bowtie$ claudiaglavam@hotmail.com

Recebido em 24/04/2020 Aceito em 24/05/2020 Publicado em 17/06/2020 
interlocutor, nos permitiu olhar para o campo da Educação Matemática como um conjunto de verdades, por vezes inquestionáveis, em determinados períodos históricos. A respeito de nosso objeto de pesquisa, percebemos que as verdades a respeito das práticas de memorização na contemporaneidade pedagógica ainda se fazem presentes, mesmo que, na atualidade, se configurem como sendo uma crítica ao ensino considerado tradicional, aquele em que o aluno "memorizava mecanicamente".

Interessante destacar que grande parte das pesquisas em Educação Matemática, mesmo não se restringindo ao tema da memorização, criticam estas práticas em detrimento de atividades lúdicas, do uso de tecnologias, da apropriação da etnomatemática e da modelagem matemática, dentre outras estratégias, conforme observamos nas buscas realizadas no Banco de Teses e Dissertações da Coordenadoria de Aperfeiçoamento de Pessoal de Nível Superior (CAPES). Encontramos apenas dois trabalhos que tem como tema central a questão da memória, ou das práticas de memorização, no ensino de Matemática: uma tese intitulada Um estudo exploratório das relações entre memória, desempenho e os procedimentos utilizados na solução de problemas matemáticos (ALVES, 2005) e uma dissertação intitulada A memória na aprendizagem matemática (FERRAZ, 2014). Alguns resultados apontados pelos trabalhos são os seguintes:

\footnotetext{
A memorização pode fazer toda a diferença no aprendizado dos alunos, desde que se foque apenas na memorização de conceitos genéricos, pois estes serão acessados com mais frequência e, dessa forma, 0 ato de memorizar será proveitoso por mais tempo (FERRAZ, 2014, p. 57).

Considerando-se que a atenção é a responsável pelo monitoramento, dando continuidade às informações retidas na memória e as informações recebidas através dos sentidos, é possível afirmar que esses sujeitos, ao receberem as novas informações, durante as aulas de Matemática, as retêm sem estabelecer relações com informações anteriores, culminando em uma aprendizagem mecânica (ALVES, 2005, p. 135)
}

Assim, observamos que tais trabalhos sugerem um viés cognitivista em relação à memorização, indicando como a memória pode contribuir para o aprendizado da Matemática, diferentemente do que pretendemos desenvolver no presente estudo. Para além de uma defesa ou de críticas a estes processos, pretendemos, antes, investigar como as concepções de memorização foram sendo reconfiguradas com o passar do tempo, mergulhadas em determinados regimes de verdade, sendo um deles advindo dos saberes psi e de seus efeitos no campo educacional.

A questão da memorização perpassa diferentes períodos históricos e por décadas vem 
sendo criticada por especialistas, especialmente o ensino da Matemática baseado nas perspectivas mnemônico-mecanicistas e empírico-intuitivas, conforme discutem Miguel e Vilela (2008). Os autores apontam ainda outra perspectiva de mobilização de cultura matemática, chamada de construtivista, baseada em argumentos advindos dos saberes da Psicologia:

\begin{abstract}
Se as perspectivas empírico-intuitivas se insurgiram contra as mnemônicomecanicistas, através da reivindicação do papel essencial que deveria ser desempenhado pela percepção sensorial em relação aos da memorização e verbalismo, a partir da década de 1970, começam a surgir as chamadas perspectivas construtivistas, reivindicando o papel fundamental da ação e da operação em relação ao da percepção sensorial (MIGUEL e VILELA, 2008, p. 103).
\end{abstract}

A perspectiva construtivista, por considerar a ação da criança no processo de aprendizagem, seja de forma concreta ou mental, se contrapõe à observação passiva dos objetos como propunha a concepção empírico-intuitiva. Assim, podemos inferir que as práticas de memorização no ensino de Matemática foram substancialmente atualizadas pelos saberes $p s i$, ou seja, pelos saberes advindos da Psicologia, e repensadas quanto aos seus objetivos e importância no aprendizado, o que nos aponta para uma possível ressignificação das práticas educacionais, e por consequente, da memorização no ensino de Matemática.

Acrescentado a isso, encontramos indícios da Neurociência que vem, na contemporaneidade, ditando novas verdades sobre a memória e suas implicações nos processos escolares. Lançamos como hipótese que a Neurociência vem ocupando um lugar de destaque na contemporaneidade no que diz respeito aos discursos relacionados à memória, no entanto, foge ao escopo deste estudo aprofundar esta discussão. Apenas levantamos como hipótese que os saberes da Neurociência corroboram para os entrelaçamentos de enunciados dos quais daremos visibilidade. A respeito deste tema, destacamos duas dissertações de mestrado, intituladas: Revista Nova Escola e Neurociência: uma discussão sobre dispositivos biopolíticos (ROSA, 2017) e Neurociência na Revista Nova Escola (BORTOLI, 2016).

Os saberes advindos do construtivismo, ou mesmo da Neurociência, acabam dando força a outros enunciados que afirmam, por exemplo, que o significado de "decorar" está relacionado à memorização sem compreensão, pois os saberes matemáticos cobrados de forma oral não fariam sentido para o estudante. Como veremos, segundo os professores, essa forma de ensino não contribui para a resolução de problemas. Com efeito, uma justificativa recorrente é aquela que aponta para a ação do estudante, como agente na construção do conhecimento, ao invés de apenas repetir o que o professor propõe. Importante destacar que os professores que defendem 
a memorização no ensino de Matemática enfatizam sempre que as metodologias não devem ser as mesmas do passado. 0 modo como os alunos memorizam fatos matemáticos não deve ser feito de forma mecânica, verbalista ou repetitiva como acreditam ter sido o ensino em outros tempos.

Para analisar estes aspectos, recorremos ao material da pesquisa que compreende exemplares da Revista Nova Escola, e das ferramentas metodológicas da análise do discurso na perspectiva foucaultiana. Posteriormente à descrição dos aspectos metodológicos, desenvolvemos a abordagem teórica sobre o construtivismo recorrendo a algumas problematizações destas teorias. Após isso, realizamos a análise das Revistas, apontando os resultados da pesquisa.

\section{A Revista Nova Escola: superfície de inscrição de discursos}

A escolha do material de pesquisa advém do caráter discursivo da Revista Nova Escola, pois a consideramos um veículo atuante e abrangente de difusão de ideias pedagógicas no Brasil, sendo assim "peça-chave para a compreensão da mecânica geral do governamento docente na atualidade" (AQUINO, 2013, p. 206). Ademais, nesta Revista circulam verdades no campo da Educação Matemática, especialmente veiculadas por especialistas portadores de uma ampla visibilidade na mídia educativa. Com efeito, as propostas didáticas sugeridas pelas Revistas são atravessadas também por estas verdades, culminando com a difusão de modelos ideais de escola, de práticas pedagógicas e de subjetividades docentes e discentes.

Desde 1986, quando da publicação do primeiro exemplar da Nova Escola até o momento atual, esta Revista expressa as principais mudanças no meio educacional, em suas reformas, teorias, leis e concepções pedagógicas. A Revista, como base empírica, pode nos colocar em tempos e lugares da Educação Matemática a partir de fragmentos que possibilitam construir outra forma de ler e interpretá-Ios. É significativo ainda dizer que consideramos a Revista Nova Escola "apenas como um lugar de inscrição de discursos que acabaram por instituir modos de se pensar e agir" neste campo de saber (DUARTE, 2009, p. 48).

Oliveira (2006) analisou tal Revista com foco na Matemática Escolar, a partir de um olhar foucaultiano. Conforme 0 autor, a Revista passa a ser um elemento articulador e de divulgação das políticas educacionais estabelecidas pelos Parâmetros Curriculares Nacionais (PCN), a partir de 1995, interferindo nas posturas político-pedagógicas dos professores brasileiros. Na mesma 
direção, Vieira (1985) aponta que nos primeiros anos de edição, anteriores aos PCN, a Revista Nova Escola produziu um discurso enfático em relação ao construtivismo, disseminando a visão de que esta seria a corrente pedagógica mais eficiente para embasar as práticas dos professores.

Ou seja, estes trabalhos evidenciam que a Revista já se constitui como influente pilar de investigação por detalhar os discursos caros aos professores da época, se tratando de inovações pedagógicas apropriadas e difundidas pelos documentos oficiais e outras políticas educacionais. Nesta esteira de trabalhos, Pedroso (1999) analisa, nas Revistas publicadas no período de 1986 a 1989, as políticas educacionais na redemocratização do Brasil. Segundo a autora, a união de interesses da editora e do Ministério da Educação (MEC) possibilitou que o Estado levasse adiante as novas mudanças educacionais, por meio da distribuição das Revistas nas escolas. Sendo assim, consideramos tais aspectos para a escolha da Revista Nova Escola como material empírico para a investigação.

Para a pesquisa desenvolvida na tese foram analisados 235 exemplares, publicados entre 1986 e 2015, e deles foram extraídas as enunciações que posteriormente formaram o corpus de análise. No manuseio inicial de todos os exemplares encontrados, por não ter ainda a precisão daquilo que iriamos encontrar em termos de enunciados, atentamos ao como e o que sinalizavam as reportagens. Aos poucos foram realizadas novas leituras, mais cuidadosas, delimitando as edições que seriam de fato analisadas. Aquelas descartadas foram as que não se referiam ao ensino de Matemática ou não mencionavam este tema em nenhum momento em toda a edição. $A$ intenção, a princípio, era mapear as enunciações que discutiam particularidades do ensino de Matemática referentes às práticas dos professores e opiniões de pesquisadores na área. Posteriormente, com o recorte estabelecido, demos ênfase àquelas que tratam das práticas de memorização ou que se relacionam a elas por meio de entrelaçamentos discursivos. Os excertos que pareciam ser importantes eram recortados e categorizados com base em aspectos como "aqueles que defendem determinada prática pedagógica", "aqueles que indicam características dos estudantes", "aqueles que apresentam exemplos de atividades" etc. No decorrer das análises e da escrita do texto, alguns excertos foram sendo descartados visto que não nos auxiliavam a responder as questões propostas. Especialmente neste artigo, recorremos a 29 excertos extraídos deste montante, o que totaliza 26 edições $^{1}$ selecionadas. Este recorte foi feito considerando os

\footnotetext{
${ }^{1}$ As enunciações utilizadas no decorrer do artigo e que fazem parte das Revistas Nova Escola aparecem dentro de retângulos para melhor destacá-las entre as outras citações, sendo que as partes mais importantes serão registradas em negrito. Nesta forma de apresentação consideramos pertinente indicar em cada excerto o número e 0 ano da Revista da qual foi extraído, ao invés de apresentar todas as Revistas nas referências bibliográficas do artigo.
} 
excertos em articulação com o referencial teórico que nos permitiu problematizar as questões ligadas aos saberes psi, articuladas ao construtivismo, especialmente. Assim, os excertos foram selecionados a partir do conjunto daqueles que aparecem com mais recorrência nas Revistas.

Como olhamos para este conjunto de elementos nas Revistas que nos conduzem ao objeto a ser estudado? Quais as lentes que nos permitem enxergar estes elementos e não outros? Segundo entendimento amplamente compartilhado e difundido por diversos autores e comentadores de Foucault, as teorizações elaboradas pelo filósofo nos fornecem ferramentas tanto teóricas quanto metodológicas, as quais procuramos explanar aqui, de modo sucinto.

As proposições sobre a análise do discurso são constituídas por diversos conceitos, como os de enunciado, formação discursiva, história, dispositivo, sujeito, acontecimento, dentre outros, e a própria concepção de discurso, entendido como

um conjunto de enunciados, na medida em que se apoiem na mesma formação discursiva; ele não forma uma unidade retórica ou formal, indefinidamente repetível e cujo aparecimento ou utilização poderíamos assinalar (e explicar, se for o caso) na história; é constituído de um número limitado de enunciados para os quais podemos definir um conjunto de condições de existência (FOUCAULT, 2008, p. 132).

Para o filósofo, um enunciado define-se pela condição de existência a partir de unidades como frases, proposições e atos de linguagem, mas não se confunde com estes elementos, pois, além deles, o enunciado é marcado por suas singularidades históricas. 0 termo enunciado é utilizado, além de outros aspectos, para diferenciá-lo do todo, dos conjuntos de discursos. Os enunciados são estabelecidos ainda a partir de enunciações. Uma enunciação se expressa sempre que um conjunto de signos é emitido, e é também um acontecimento, mas que não se repete, ao contrário do enunciado. Um enunciado pode ser composto por múltiplas enunciações. Como explicou Foucault (2008), quando uma pessoa diz algo, podemos tomar esta fala como uma enunciação. Se outra pessoa diz o mesmo e ao mesmo tempo, avaliamos que existem duas enunciações, o que expressa sua singularidade. De tal modo, para uma especulação histórica pode-se analisar enunciações que produzem enunciados naturalizados como verdades em diferentes épocas.

O discurso da Educação Matemática, por exemplo, pode ser constituído por diversos enunciados que foram se reconfigurando com o passar do tempo, tornando-se verdades em uma época e não em outras. Incluem-se aí os enunciados referentes à memorização e suas derivações e sentidos atribuídos pela Revista. Assim, os enunciados visualizados nas Revistas emergem de 
enunciações como as falas dos sujeitos que compõem o espaço escolar, os relatos de práticas pedagógicas, as sugestões de pesquisadores na área etc.

Elegendo Foucault como nosso interlocutor teórico, pretendemos evidenciar nas Revistas as enunciações a respeito das práticas de memorização em diferentes épocas, e dar atenção às subjetividades que estavam/estão sendo produzidas e disponibilizadas, uma vez que nesta perspectiva, existe uma relação entre os discursos e a formação de subjetividades. Este trabalho analisa os enunciados que atravessam o campo da Educação Matemática, entendendo-os a partir de um tempo, um lugar e uma positividade concreta por meio de práticas e instituições.

\section{Teorizações para (re)pensar o construtivismo}

Podemos iniciar esta discussão a partir das modalidades enunciativas das quais trata Foucault (2008) ao se referir à linguagem utilizada em diferentes espaços e épocas, questionando, por exemplo, o sujeito que fala, a posição de onde fala e quais os efeitos para aqueles que estão incluídos nas relações que perpassam a fala. A linguagem advinda de saberes considerados científicos permite que algumas coisas se tornem dizíveis e visíveis, ou seja, "aparecem como um agenciamento de práticas discursivas" (ROSE, 2001, p. 151).

Como afirma Rose (2001), o corpo de discursos da Psicologia, por exemplo, tem significativa importância nos agenciamentos de subjetivação na contemporaneidade. Especialmente no campo educacional, os saberes psi produziram verdades que mobilizaram novas alternativas para a Educação. As próprias práticas relacionadas à memória para fins educacionais têm sido redimensionadas em decorrência de tais saberes, como afirma a autora:

As práticas da pedagogia têm, obviamente, inventado toda uma gama de outras técnicas de memória, buscando inculcá-las nas salas de aula, tendo proliferado ao longo da experiência de quase todos os humanos contemporâneos e tendo sido elas próprias alimentadas pelas disciplinas psi (ROSE, 2001, p. 163).

Os saberes psi no campo educacional tiveram ampla visibilidade por vias do construtivismo. A partir da década de 1960, o ensino de Matemática foi influenciado pela tendência construtivista que teve como precursor Piaget, e após 1980 adquire maior visibilidade nos grupos de pesquisas brasileiros, o que nos leva a entender esse período como produtivo para a educação brasileira em termos de renovação das práticas pedagógicas.

De acordo com Becker (1994), em um amplo sentido, isto é, filosófico, científico e 
epistemológico piagetiano, o construtivismo significa que o conhecimento não é algo terminado em nenhuma instância, isto é, nada está pronto ou acabado. Este aspecto faz com que ele seja constituído pela interação do indivíduo inserido em um meio físico e social, caracterizado pelo simbolismo humano e pelo mundo das relações do trabalho, mas também, e principalmente, pela força da ação deste indivíduo, sem relação com prévias habilidades, o que implica que "antes da ação não há psiquismo nem consciência e, muito menos pensamento" (BECKER, 1994, p. 2). Ampliando esta noção, o autor inclui outros elementos que auxiliam a situar ainda mais precisamente o construtivismo:

\begin{abstract}
Construtivismo é, portanto, uma ideia; melhor, uma teoria, um modo de ser do conhecimento ou um movimento do pensamento que emerge do avanço das ciências e da Filosofia dos últimos séculos. Uma teoria que nos permite interpretar o mundo em que vivemos. No caso de Piaget, o mundo do conhecimento: sua gênese e seu desenvolvimento. Construtivismo não é uma prática ou um método; não é uma técnica de ensino nem uma forma de aprendizagem; não é um projeto escolar; é, sim, uma teoria que permite (re)interpretar todas essas coisas, jogando-nos para dentro do movimento da História - da Humanidade e do Universo. Não se pode esquecer que, em Piaget, aprendizagem só tem sentido na medida em que coincide com o processo de desenvolvimento do conhecimento, com o movimento das estruturas da consciência. Por isso, se parece esquisito dizer que um método é construtivista, dizer que um currículo é construtivista parece mais ainda (BECKER, 1994, p. 2-3).
\end{abstract}

Do ponto de vista educacional, o autor situa o construtivismo como uma forma teórica para a qual convergem várias tendências da Educação que possuem em comum "a insatisfação com um sistema educacional que teima (ideologia) em continuar essa forma particular de transmissão que é a Escola, que consiste em fazer repetir, recitar, aprender, ensinar o que já está pronto" (BECKER, 1994,, p. 3). Em oposição, a partir da realidade de alunos e professores, o construtivismo propõe uma ação mais dinâmica que visa a criação e construção do conhecimento que ocorre em condição de complementaridade entre sujeitos da escola, os problemas sociais e o próprio conhecimento.

Em outras palavras, Duarte (2009) afirma que as confrontações entre as práticas que pareciam antagônicas deveriam ser eliminadas e, para tanto, era preciso ajustar os mecanismos de funcionamento destas e definir novas táticas. Assim, fazia-se necessário

minimizar a passividade dos alunos no processo de aprendizagem em prol de uma participação mais ativa e conferir um "cunho de naturalidade" a esse processo fazia parte das ambições da escola de meados do século XX. Era, então, necessário alterar aquele processo para que as crianças não se tornassem "simples papagaios", condição essa que seria nefasta e contrária a uma aprendizagem nos moldes das novas orientações pedagógicas da época, que se propunham reforçar, dentre outras coisas, a relação entre as aprendizagens escolares e a "realidade" extraescolar. 
Assim, uma escola marcada pela mecanização "tradicional" se serviria de estratégias que a aproximariam das premissas da Escola Progressista (DUARTE, 2009, p. 112).

Ademais, segundo Corazza (1996, p. 216), o construtivismo é uma prática discursiva, já que vai além da produção de discursos, podendo ser entendido como "uma prática que toma corpo em processos técnicos, em instituições, em padrões de comportamento geral, em formas de se transmitir e difundir, e em formas pedagógicas que são historicamente produzidas no contexto de relações de poder-saber específicas". No entanto, a autora destaca que o construtivismo não é algo novo no sentido de uma racionalidade inaugural, ou mais "evoluído" em relação às verdades em que se baseiam as práticas pedagógicas anteriores, mas uma repetição que consiste em "fazer coisas velhas de um jeito supostamente novo" (CORAZZA, 1996, p. 218). Tal repetição se refere aos discursos produzidos na Modernidade, com o surgimento do sentimento de infância que não existia na Idade Média, o que acarretou novos modos de governar as crianças por meio da escolarização:

\footnotetext{
Um discurso pedagógico que - apenas para apresentar três históricos pontos- chave - tem em Rousseau, filósofo francês do século XVIII, um de seus fundadores, ao colocar a necessidade de "conhecer" a criança e a infância para melhor poder educálas, de forma "natural"; na Escola Ativa das primeiras décadas de nosso século sua principal seguidora e operadora deste tipo de conhecimento no espaço escolar institucionalizado; e no discurso construtivista contemporâneo sua vontade de saber mais elaborada e sua vontade de poder mais desenvolvida, minuciosa e eficiente (CORAZZA, 1996, p. 218).
}

A autora descreveu o Brasil em sua transição para as políticas educacionais do Estado neoliberal, inferindo que o país passava, na década de 1990, por um processo de "desconstrutivismo" político em que a educação pública caminhava em direção à educação vista como "mercadoria", ou mais precisamente, à privatização. Este desconstrutivismo, ou desmontagem, como denomina a autora, se refere à deterioração do sistema público de ensino, dos salários dos professores, bem como de suas formações, às condições precárias das escolas, ao fracasso escolar dos estudantes etc. Se, por um lado, ocorria esta desconstrução política, 0 discurso educacional reforçava a ideia de uma "construção" pedagógica que estaria por vir, baseada na defesa "do alfabetismo, de conhecimento, da língua escrita, do currículo, da inteligência, do desenvolvimento infantil, do sujeito autônomo e independente, da emancipação, da cidadania responsável, da gestão democrática das escolas, da carreira docente etc." (CORAZZA, 1996, p. 222). Ocorria, então, um paradoxo, segundo a autora, pois o construtivismo pedagógico poderia "estar servindo como crença, como "verdade" de que necessita o Estado 
neoliberal para instalar suas políticas educacionais descontrutivistas" (CORAZZA, 1996, p. 222).

Assim, a partir destas considerações empreendidas por Corazza (1996), consideramos que novas formas de subjetividades foram sendo implementadas a partir do construtivismo, amparado no regime discursivo dos saberes psi, que ao mesmo tempo produz e é produto de um país em constantes mudanças políticas e econômicas. Diante deste entendimento do construtivismo como prática discursiva, é possível nos colocarmos em outras posições de análise das práticas de memorização no discurso da Educação Matemática, levando em conta tais transições de ordem global. A correlação da perspectiva construtivista com aspectos mais amplos do social, como a questão do neoliberalismo, nos permite analisar as práticas educacionais num campo de força maior, a partir das práticas fronteiriças que se articulam. Vejamos, primeiramente, algumas características do construtivismo em operação no discurso da Educação Matemática.

\section{Uma análise das práticas de memorização}

Um aspecto fundamental defendido por esta perspectiva, como já apontado, diz respeito à construção do conhecimento. A aprendizagem do conhecimento matemático na visão construtivista é adquirida a partir da relação do estudante com o meio em que vive, de forma interativa e reflexiva, pois o saber é construído pelo próprio aluno e facilitado pelo professor, em um processo coletivo. Na Revista Nova Escola é possível encontrar críticas referentes aos processos de memorização mecânica que enfatizam a importância de mobilizar ações em que 0 estudante possa ser o agente na construção do conhecimento, como apontam as seguintes enunciações:

\footnotetext{
Suponhamos que você, professor de Matemática, chegou ao ponto do currículo em que precisa ensinar quantos milímetros cabem em 1 litro. Qual estratégia é mais eficaz: anotar no quadro a equivalência " $1 \mathrm{l}=1000 \mathrm{ml}$ " e pedir que os alunos a memorizem? Ou leva-los a perceber qual é a relação entre as unidades por meio de uma atividade que envolva, digamos, copos de 250 mililitros e uma jarra de um litro? Nunca é demais lembrar que a melhor alternativa é aquela em que 0 aluno tem a oportunidade de testar hipóteses para construir o conhecimento (NE, n. 222, 2009, p. 68, grifos nossos).
}

Contra a matemática verbalista, fragmentada, desconexa, que leva 0 aluno a decorar sem compreender o significado dos conceitos, essas experiências procuram dar um novo sentido ao ensino da disciplina. Nelas são usados materiais concretos, brincadeiras, fatos do dia a dia da criança sempre tentando levar o aluno a compreender o significado matemático e a construir o seu próprio conhecimento (NE, n. 39, 1990, p. 14, grifos nossos).

"O aluno aprende. É só você parar de ensinar". [...] A proposta é inspirada nas lições do suíço Jean Piaget e baseia-se no método de aprendizagem espontânea: a Matemática deixa de 
ser ensinada através da linguagem dos símbolos e passa a emergir espontaneamente da própria criança. Ou seja, a Matemática é construída pela criança. O professor apenas facilita esse processo de construção, que deve ser necessariamente prazeroso (NE, n. 12, 1987, p. 11, grifos nossos).

Assim, vemos que nestas reportagens existe uma dicotomia entre decorar e construir o conhecimento, já que na primeira o conhecimento estaria dado de antemão, cabendo ao estudante somente memorizá-lo. Ao contrário, o professor deve ser o facilitador do processo e o estudante o protagonista. Assim, especialistas consideram que a Matemática, ao menos em um nível escolar, não é somente abstrata e lógica, mas deve partir do concreto, da realidade, para ser "construída" pelos educandos e fazer sentido para eles.

Por vias do construtivismo, muitos professores ainda hoje consideram que é necessário memorizar os conteúdos, mas sem sofrimento por parte do estudante, pois provavelmente não é mais imprescindível que ele mostre "em voz alta", perante a turma e ao professor, que assimilou determinado saber. Assim, de acordo com esta perspectiva, as posições de sujeito que 0 estudante e o professor passam a ocupar e as novas relações de poder que perpassam a sala de aula são aquelas em que o estudante é a centralidade e os métodos de ensino são pautados em suas necessidades.

Neste contexto, é consenso que a memorização é um efeito do processo de compreensão por parte do estudante, não de forma mecânica, mas por meio de uma repetição que só será aceita se fizer sentido para 0 aluno. Os trechos abaixo, provenientes das Revistas, denotam a importância da repetição e do decorar significativos:

Nós, os "construtivistas", costumamos associar esse ato com um decorar sem sentido para quem o faz. Pensando nisso, ocorreu-me verificar que há, pelo menos, outros três propósitos para a repetição. O primeiro é aprender o que observamos e vivemos na experiência, ou seja, repetir para duplicar ou imitar. O segundo propósito é para apreciar. Isso acontece no campo das artes e da religião ou na convivência com pessoas e coisas [...] Há um terceiro propósito que é repetir para compreender. Penso que é nesse ponto que as pessoas mais divergem. "Não construtivistas" julgam que aprender pressupõe, dentre muitos outros aspectos, repetir para memorizar, decorar, até que algo se torne um hábito ou costume, evitando erros ou confusões [...] Mas é importante fazer uma distinção para não confundir qualquer repetir com aprender, nem qualquer aprender com repetir (NE, n. 286, 2015, p. 58, grifos nossos).

O matemático espanhol Carlos Maza Gómez observa no livro Multiplicar y Dividir - A Través de la Resolución de Problemas que o trabalho com a memorização ocorre de três maneiras: a primeira aponta para a repetição de resultados até que eles sejam guardados na memória, enquanto a segunda se dá quando os resultados fazem parte de uma sequência - por exemplo, decorar a tabuada do dois, depois a do três e assim por diante, criando relações entre elas. Para o autor, esses dois caminhos, que predominaram nas escolas durante boa parte do século passado, não são os mais adequados. A "terceira via", proposta por Gómez, consiste em fazer com que 0 aluno decore os resultados sem criar vínculo com a 
sequência - e, claro, apenas depois de entender o cálculo (NE, n. 225, 2009, p. 93, grifos nossos).

Quando fazem sentido, os conhecimentos são facilmente aplicados, como se a pessoa tivesse nascido com eles. São tão bem apropriados que parecem fazer parte da gente naquilo que há de mais nuclear: o nosso coração. Aliás, esse sentido original da expressão "de cor" (do latim cuore, coração). Em inglês também se diz learn by heart, isto é, aprender pelo coração. Contudo, o tempo fez com que "de cor" passasse a ser identificado com algo que é seu oposto, a nefasta "decoreba". É um exemplo da força que o processo de construção de sentidos tem. Fica aqui então um convite ao atrevido exercício de "ressignificar" — dar um outro sentido ou promover o retorno ao seu original. Nesse caso, seria voltar a dizer que o conhecimento significativo é aquele que se hospeda em nosso coração (NE, n. 177, 2004, p. 18, grifos nossos).

Uma pesquisa sobre determinados fatos numéricos, feita por mim e mais dois colaboradores com turmas de $4^{\mathrm{a}}, 5^{\mathrm{a}}$, e $6^{\mathrm{a}}$ séries, mostrou a inutilidade da memorização pura e simples. Uma das perguntas era "Quanto é 6x3?" Quase todos os jovens responderam corretamente. Mas, quando pedimos para relacionar a questão com uma situação da vida real ou para fazer uma frase na qual aparecesse o fato de que $6 \times 3=18$, os resultados mudaram drasticamente: $75 \%$ dos alunos de $4^{\text {a }}$ série, $85 \%$ dos de $5^{\text {a }}$ série e $30 \%$ dos de $6^{\text {a }}$ falharam em criar um exemplo de multiplicação (NE, n. 134, 2000, p. 13, grifos nossos).

A tabuada é fundamental para o dia-a-dia do aluno, mas ela não deve ser ensinada como antigamente. $O$ ideal é que a criança reconheça a necessidade de fazer contas no seu cotidiano. Antes de chegar à memorização, é aconselhável usar estratégias como receitas culinárias e visitas a feiras. São lições úteis para o resto da vida (NE, n. 190, 2006, p. 18, grifos nossos).

Os excertos apontam que repetir para exclusivamente memorizar não são técnicas eficazes, e um dos motivos é que os estudantes não conseguem aplicar os resultados que foram decorados em um tema do seu cotidiano, o que mostra que não assimilaram de forma adequada o conteúdo. Por outro lado, a assim chamada "memorização compreensiva", que vincula a repetição ao um processo mais complexo que envolve um entendimento mais amplo do objeto a ser estudado, passa a ser referendada inclusive pelos documentos oficiais, como os PCN (BRASIL, 1998). Aliás, é importante destacar a forte relação da emergência dos PCN com 0 construtivismo, pois como afirma Corazza (1996, p. 222), estes documentos são

fortemente inspirados pelas bases teóricas da psicologia e da epistemologia genéticas e interacionistas-sociais e da psicopedagogia - presentes em todos os textos de todos os documentos -, as quais constituem seu "viés psicologizante" por excelência. Sem falar do processo de sua elaboração, os PCN - que nada mais são do que 0 verdadeiro "currículo nacional" e a base programática dos "exames nacionais" assumem e explicitam a forte conexão que os/as especialistas do MEC estabelecem entre a constatação dos baixos desempenhos educacionais das crianças das escolas públicas e - em seu diagnóstico - a inadequação das propostas curriculares e metodológicas que vêm sendo feitas; cuja "correção" e "adequação" são justamente fixadas, tendo por paradigma central as teorias construtivistas.

Os PCN defendem que o aprendizado matemático deve estar associado à relação que 0 
estudante estabelece entre os resultados matemáticos e sua realidade: "a atividade matemática escolar não é olhar para coisas prontas e definitivas, mas a construção e a apropriação de um conhecimento pelo aluno, que se servirá dele para compreender e transformar sua realidade" (BRASIL, 1998, p. 56). Por meio de atividades do cotidiano é possível que o estudante memorize, visto que desta maneira realiza uma reflexão sobre o conhecimento, mostrando então que compreendeu aquilo que decorou. "É necessário que o aluno entenda o que está memorizando" se tornou um enunciado recorrente nas Revistas e aparece com regularidade nas propostas pedagógicas evidenciadas nestas reportagens:

Carretero lembra-se com pesar das aulas rígidas na Educação Básica. "A única resposta que eu recebia era: guarde as informações de memória" [...] 0 mais importante é compreender o conceito e usá-lo - não decorá-lo. Devemos construir aprendizagens significativas. (NE, n. 163, 2002, p. 21, grifos nossos).].

Aprender não é só memorizar informações. É preciso saber relacioná-las, ressignificá-las e refletir sobre elas. É tarefa do professor, então, apresentar bons pontos de ancoragem, para que os conteúdos sejam aprendidos e fiquem na memória, e dar condições para que 0 aluno construa sentido sobre o que está vendo em sala (NE, n. 253, 2012, p. 55, grifos nossos).

Bigode ilustra a vantagem de 0 aluno se tornar sujeito da atividade com um antigo provérbio chinês, atribuído a Confúcio: "se ouço, esqueço; se olho, recordo; se faço, compreendo" (NE, n. 173,2004, p. 43 , grifos nossos).

"Antes, quando pedia para os estudantes calcularem a área de uma figura plana, eles perguntavam: 'É para somar ou multiplicar?', expressando dúvidas típicas de quem memoriza algo sem entender". Agora, todos sabem o que está envolvido em cada fórmula e o motivo (NE, n. 259, 2007, p. 61, grifos nossos).

"Por que é um mito - Apenas copiar ou fazer exercícios repetitivos não garante a aprendizagem dos alunos. [....] "Para aprender não é suficiente repetir um conteúdo ou memoriza-lo. Somente é possível aprender quando há reflexão sobre aquilo que se faz (NE, n. 240, 2011, p. 42, grifos nossos).

[...] depois de um planejamento que envolve a resolução de problemas, levando-os a raciocinar e a refletir sobre as estratégias que usam, é interessante apresentar atividades que ajudem na memorização da tabuada, com as propostas no quadro da página ao lado, e o jogo Labirinto, disponível no site. "O segredo é propor desafios que façam sentido, ao mesmo tempo que permitam a compreensão da estrutura e das propriedades dos números e das operações" (NE, n. 209, 2008, p. 59-60, grifos nossos).

"As pessoas acham que o bom matemático é aquele que sabe fazer contas mirabolantes. Não é verdade. Em geral, os melhores têm aversão a esse tipo de operação". A frase é de Rui Lopes Viana Filho, medalha de ouro na $39^{\mathrm{a}}$ Olimpíada Internacional de Matemática. Ora, se até os "crânios" têm aversão às contas mirabolantes, por que a escola insiste em ensiná-las? 0 chamado conteúdo obsoleto, sem significado para o aluno, é um dos principais entraves da disciplina na escola, concordam todos os especialistas. (NE, n. 148, 2001, p. 54 , grifos nossos).

Importante observar que todas as afirmações sugestivas das potencialidades da reflexão 
e da compreensão são acompanhadas de ponderações feitas à memorização reveladas a partir dos entendimentos de repetição. A seguir, fazemos alusão ainda a outras enunciações que estão ligadas aos saberes psi por discutirem o uso da memória no ensino e na aprendizagem, bem como aspectos do pensamento matemático que levam em consideração estruturas cognitivas por permitirem a sua apropriação por parte do estudante.

"Todos os estudantes dos primeiros anos do Ensino Fundamental têm que vivenciar os números e experimentá-los de diferentes formas. Esse trabalho colabora para que o pensamento matemático ganhe elasticidade necessária." Graziela entende que o algoritmo não pode ser deixado de lado - afinal, é uma maneira econômica de fazer contas, mas deve ser introduzido somente numa etapa posterior (NE, n. 201, 2007, p. 72, grifos nossos).

NE: Saber de cor conceitos, dados e fatos matemáticos não é um sinal de que eles foram aprendidos? O'Brien: De forma alguma! É preciso deixar claro que eu não tenho nada contra a memória em si. Acho que ela é muito importante - para compreender isso, basta ver uma pessoa que sofra de Alzheimer, às vezes incapacitada de lembrar o próprio nome. Mas, no meu entender, a memória é apenas uma de nossas muitas capacidades intelectuais. No caso da educação matemática, mesmo na faixa dos 5 ou 6 anos, é a constituição de uma intrincada teia de ideias que leva ao saber, não uma coleção de fatos prontos apresentados a ela (NE, n. 134, 2000, p. 12-13, grifos nossos).

A primeira enunciação, referida por uma professora do Ensino Fundamental, aponta para a elasticidade do pensamento matemático que deve ser desenvolvida sem a utilização de algoritmos inicialmente. Já para o professor O'Brien, a memória como capacidade intelectual é importante, no entanto o pensamento matemático não é assimilado a partir de fatos simplesmente decorados. Este fato incorporado ao enunciado da memorização não mecanizada é efeito de diversos discursos, que assim como os saberes psi, possui o status de saber científico, e no campo da Educação adquiriu potência nas últimas décadas.

De acordo com Silva e Vaz (2016), durante o século XX as ciências psi tentaram compreender o sujeito, mas na contemporaneidade elas não são mais suficientes, e entram em cena estas outras verdades sobre a atividade cerebral. Conforme os autores, existe um grande investimento sobre o cérebro na atualidade, seja para aumentar sua eficiência a partir da concentração e da atenção do ser humano, seja para garantir um controle sobre suas emoções. Neste contexto, o cérebro adquiriu um protagonismo das pesquisas referentes ao comportamento humano, especialmente pela ascensão das pesquisas em neurociência. Mesmo com as controvérsias a respeito das interpretações das imagens do cérebro, conforme as teorizações foucaultianas, "as técnicas de visualização e produção de imagens do corpo passaram a produzir "verdades"'” (SILVA e VAZ, 2016, p. 214). 
Nesta perspectiva, desenvolvem-se pesquisas objetivando maximizar o capital mental dos indivíduos, apresentar diagnósticos de desempenho e até mesmo diagnosticar patologias. Tais aspectos são introduzidos também no campo educacional, relacionadas aos contextos de ensino e de aprendizagem. Neste sentido, os autores teorizam sobre a constituição de um sujeito cerebral e as implicações destas subjetividades para o campo da Educação, que vem buscando também "agir sobre, por meio do cérebro - governar pelo cérebro" (SILVA e VAZ, 2016, p. 224).

$\mathrm{Na}$ Educação, alguns enunciados são produzidos ou reforçados por estas teorias: "devese considerar o conhecimento prévio do aluno"; "é preciso trabalhar com as emoções em sala de aula, substituindo o medo pelo prazer de aprender"; "é necessário desenvolver os diversos tipos de memória", dentre outros. Os discursos da Educação Matemática, especialmente aqueles veiculados pela Revista Nova Escola, se apropriam de tais verdades, justificando a necessidade de desenvolver as diferentes inteligências e partes da memória, não só aquela baseada em repetições e memorização de fatos e fórmulas.

"A mente é uma máquina que trabalha a base de recompensas e punições. Porém, o medo de ser repreendido causa estresse", afirma Sidarta Ribeiro. [...] Mais proveitoso em sala de aula é provocar boas emoções, aliando a sensação de prazer ao conhecimento. [...] "Criar situações interessantes para ensinar vai fazer com que 0 aluno associe 0 aprendizado ao prazer" (NE, n. 179, 2005, p. 57, grifos nossos).

Nos últimos 20 anos, a neurociência avançou muito nas descobertas sobre o funcionamento do cérebro. Hoje sabe-se o que acontece quando ele está captando, analisando e transformando estímulos em conhecimento e o que ocorre nas células nervosas quando elas são requisitadas a se lembrar do que já foi aprendido. "Com isso o professor pode aprimorar suas estratégias de ensino", diz o neuropsiquiatra Everton Sougey. Estão provadas, por exemplo, as vantagens de estabelecer ligações com o conhecimento prévio do aluno ao introduzir um novo assunto e de trabalhar também a emoção em sala de aula. 0 cérebro responde positivamente a essas situações, ajudando a fixar não somente fatos, mas também conceitos e procedimentos. [...] essa capacidade mental, relacionada a repetições, foi estigmatizada como uma das barreiras para a verdadeira aprendizagem. Nos últimos 20 anos, pesquisas apontaram a existência de vários tipos de memória, todas elas essenciais na aquisição do conhecimento (NE, n. 163, 2003, p. 43-44, grifos nossos).

É preciso motivação para aprender. A atenção é fundamental na aprendizagem. $O$ cérebro se modifica em contato com o meio durante toda a vida. A formação da memória é mais efetiva quando a nova informação é associada a um conhecimento prévio. Para você, estas afirmações podem não ser inovadoras, seja por causa da sua experiência em sala de aula, seja por ter estudado Jean Piaget (1896-1980), Lev Vygotsky (1896-1934), Henri Wallon (1879-1962) e David Ausubel (1918-2008), a maioria da área da Psicologia cognitiva. A novidade é que as conclusões são fruto de investigações neurológicas recentes sobre o funcionamento cerebral (NE, n. 253, 2012, p. 49, grifos nossos).

É possível dançar, ler, desenhar, cantar, tocar Matemática? Se você vacilou entes de responder, pensando que Matemática é só número, prepare-se para conhecer uma experiência de ensino da disciplina que integra todas essas atividades. $\mathbf{O}$ programa baseiase numa nova concepção científica da mente, a Teoria das Inteligências Múltiplas (NE, n. 101, 1997, p. 9, grifos nossos). 
Mesmo que as boas emoções representem um argumento bastante utilizado para fundamentar as escolhas que os professores fazem, configurando-se em um aspecto relacionado à Psicologia, também oferecem respaldo para uma das premissas do construtivismo: a de considerar o conhecimento prévio do estudante. O compartilhamento destas enunciações pelo campo da Psicologia Cognitivista e pela Medicina gera verdades que inevitavelmente produzem os sujeitos da Educação: sejam as subjetividades docentes, pela forma como se relacionam com tais discursos, sejam os alunos que são impactados pelas estratégias que os professores criam baseados nas estratégias que consideram pertinentes.

Podemos ainda questionar como os saberes psi atuam de forma a controlar as atividades por meio do corpo. Como viemos discutindo de acordo com Foucault (2011, p. 146), o corpo é investido pelas diversas formas de poder: "O poder penetrou no corpo, encontra-se exposto no próprio corpo", nele se encontram os efeitos dos aparatos disciplinares que a escola disseminou e ainda dissemina. Na sociedade de controle, podemos observar outras formas de exercitar 0 corpo, tornando-o lugar de inscrição dos discursos educacionais reatualizados. Por meio da Educação Matemática, se exige um corpo em movimento, porém não se trata daquele movimento ritmado, com precisão que seguia uma uniformidade.

Trata-se de atividades corporais que estimulem as "diferentes inteligências" dos estudantes, que podem ser instigadas pela Matemática. 0 jogo da amarelinha, a gincana de números, teatros com tangram e atividade envolvendo unidades de medida, por exemplo, exercitam a inteligência corporal-cinestésica e interpessoal que desenvolvem a inteligência matemática, segundo a Teoria das Inteligências Múltiplas, explicada na reportagem de 1999. Nesta perspectiva, cada sujeito possui uma habilidade que lhe é própria, e esta deve ser utilizada para estimular outras inteligências das quais tem dificuldade, entre elas, a matemática.

Se exigida de modo mecânico, a memorização da tabuada é um problema para a maioria
dos alunos. Atividades envolvendo músicas e torneios facilitam a tarefa. Na segunda
série, a gincana dos números é precedida por brincadeiras com cantigas de roda que
relacionam adição e multiplicação. [...] Inteligências envolvidas: corporal-cinestésica, espacial,
interpessoal (NE, n. 101, 1997, p. 14, grifos nossos).

Assim, embora alguns professores enfatizem a importância da memorização nas Revistas, alertam que esta não deve ser mais cobrada de forma mecanizada, mas utilizando-se de metodologias que tragam sentido aos conteúdos e divirtam os estudantes. Tanto os PCN quanto os discursos da Psicologia de modo geral ressaltam o prazer do estudante ao aprender brincando, 
aspecto que estimularia o ensino pelo concreto e especialmente por atividades lúdicas. Se a memorização da tabuada, por exemplo, for requerida pelo professor, esta deve ser feita de modo agradável para a criança, não como era feita "antigamente" em que tal atividade configurava-se como sofrimento para o estudante. Um exemplo é o excerto abaixo, de uma professora que defende a memorização por meio do lúdico. As seguintes enunciações retratam esta ação exitosa dos jogos e brincadeiras no ensino de Matemática:

Duas especialistas criam mais de trinta jogos e atividades que facilitam a memorização da tabuada. Tem que decorar, sim. Mas também dá para aprender sem sofrer (NE, n. 90 , 1995, p. 20, grifos nossos).

Habituado ao contentamento das crianças diante da nova proposta para a árdua tarefa de decorar as diversas tabuadas, o professor Eduardo conta que, nos jogos em equipe, até torcidas as crianças organizam, transformando as aulas em animadas brincadeiras. [...] Dedo no gatilho é um dos jogos mais aguardados por toda classe. Na hora de marcar os resultados nos dois cartazes o professor deve tomar o cuidado para não ser repetitivo e contemplar as diversas tabuadas (NE, n. 44, 1990, p. 26, grifos nossos).

Os jogos e os contos de Malba voltam-se para o aprendizado moral, hoje valorizado. [...] isso substitui com vantagens a rotina exaustiva e enfadonha dos exercícios e deocrebas. "O objetivo dele era ajudar a própria criança a concluir e isso eliminaria a necessidade de repetição", explica Lorenzato (NE, n. 182, 2005, p. 35, grifos nossos).

Conforme apontam as enunciações, 0 ato de decorar não deve causar sofrimento ao estudante, pois a intenção é que ele aprenda de forma prazerosa, principal objetivo das atividades lúdicas utlizadas para fins educativos. Inclusive, estas atividades se contrapõem ao exercício mecânico e repetitivo, como ressaltado nos dois últimos excertos.

Recitar um conteúdo em voz alta, cada estudante em sua vez, perante o professor, foi sendo uma prática problematizada pelos moldes das novas orientações pedagógicas. Cantar e dançar nas aulas de Matemática são práticas que, por meio do uso do corpo, parecem naturais às crianças, segundo os professores, pois aprendem com entusiasmo e "sem ansiedade". No entanto, cabe destacar que o desenvolvimento das inteligências dos estudantes por meio de técnicas que se utilizam do corpo, tais como "dançar e cantar Matemática" não estão sendo utilizadas com o mesmo objetivo daquelas expressadas pela Escola Nova que visavam docilizar o espírito por meio de tais atividades. Para além do objetivo de estimular a compreensão, por meio de tais atividades o professor deseja "conquistar os alunos" e "acabar com a ansiedade", conforme apontam os excertos:

Estudar ângulo somente por meio de desenhos no livro e no caderno não é suficiente para que a turma compreenda e utilize o conceito de ângulo na resolução de problemas matemáticos e 
no dia-a-dia. Segundo Luiz Márcio Imenes, professor de Matemática e autor de livros didáticos, se o professor leva a criança a usar o próprio corpo fica mais fácil para ela compreender o que é ângulo (NE, n. 176, 2004, p. 49, grifos nossos).

Adeus, ansiedade. 0 índice de repetência na disciplina caiu praticamente a zero. "Agora os alunos reagem à Matemática de forma muito diferente, sem ansiedade", observa Heloisa de Almeida, professora da segunda série. "As crianças não estranham que se cante ou dance para aprender Matemática”, diz Katia (NE, n. 101, 1997, p. 9, grifos nossos).

Todos em roda. Bate o pandeiro, soa o atabaque, vibram os berimbaus. É capoeira. No meio dois jogando. Um pé aqui, outro ali. Aquele para o lado, o segundo mais atrás. Gira, lenta, uma estrela no ar. Na palma da mão, alunos envolvidos, motivados, contentes... Geometria plural? A professora carioca Adriana de Souza Lima encontrou na capoeira - e, sim, na geometria que ela desenha no chão e no ar - o caminho para conquistar uma turma de 26 crianças da Escola Municipal Jônatas Serrano (NE, n. 154, 2002, p. 28, grifos nossos).

Neste contexto do envolvimento da Matemática com as práticas corporais, vemos uma gama de possibilidades: algumas mais diretas que fazem do corpo aporte para representar a Matemática como no uso de braços e pernas para fazer ângulos ou no uso dos dedos para representar quantidades que remetem ao resultado de uma operação; outras recorrem a linguagens como a dança e a música para materializar meios que supostamente favoreceriam 0 ensino de Matemática, já que estariam ligados às múltiplas inteligências exercitadas pelos estudantes.

Assim, observamos, a partir das perspectivas advindas dos saberes psi, algumas ressignificações nas práticas de memorização por meio do discurso da Educação Matemática presentes nas Revistas. Para além dos processos de compreensão do conteúdo em detrimento da repetição mecânica, e do uso do corpo para a memorização pelo prazer de aprender e não pelo "medo", podemos inferir que o construtivismo possibilitou a emergência de novas formas-sujeito da Educação. Assim, lançamos alguns questionamentos: Qual a posição que o estudante e 0 professor passam a ocupar? Que novas subjetividades estão sendo formadas pela escola com referência nestes saberes?

\section{Para concluir...}

Com a visibilidade dos saberes psi, novas propostas educacionais, como é o caso do construtivismo, produziram discursos que apontam outras condições de possibilidade para as críticas a respeito das práticas de memorização. Especialmente 0 enunciado que afirma que 0 estudante é construtor do conhecimento e que o professor não deve oferecer algo pronto a fim de que apenas se memorize adquiriu força e mobilizou novas estratégias, como é o caso do uso de 
materiais concretos no ensino de Matemática. Assim, a simples retenção de fórmulas, resultados e algoritmos é questionada em detrimento de um aprendizado significativo e com compreensão por parte do aluno.

Neste contexto, podemos inferir que os discursos provenientes da Psicologia e abordagens psicoanalistas se entrelaçam e funcionam como vetores de potência que sustentam o enunciado: "a memorização só é válida se houver compreensão". Além disto, tais discursos estarem legitimados nos PCN garante seu empoderamento no campo educativo. Observamos, portanto, que o enunciado sobre a importância ou não da memorização se entrelaça a outros que o sustentam. Deste modo, tivemos a intenção de

compreender o enunciado na estreiteza e singularidade de sua situação; de determinar as condições de sua existência, de fixar seus limites da forma mais justa, de estabelecer suas correlações com os outros enunciados a que pode estar ligado, de mostrar que outras formas de enunciações exclui (FOUCAULT, 2008, p. 31).

Cabe enfatizar ainda o lugar privilegiado que ocupa o saber advindo da Psicologia, também responsável por conduzir condutas, regular e normatizar tanto o sujeito professor, como o sujeito estudante. Deste modo, estes saberes atuam nos processos de produção de subjetividades, constituindo, como denominou Silva (1998), criaturas psi.

Assim, para além de um juízo de valor sobre as conclusões a que chegamos até aqui, ficam algumas indagações, que abrem ainda alternativas de reflexão. A exemplo disso, concordamos com Corazza (1996) quando afirma que talvez esta modulação dos estudantes a fim de constituí-los autônomos, críticos, independes, criativos etc., possa ser um aspecto problematizado quando investigamos a constituição da infância em nossos tempos:

\footnotetext{
Estaremos fortalecendo, com nossas práticas pedagógicas construtivistas, aquilo que vem sendo chamado de "fim da infância"? Em outras palavras, o que estamos fazendo com aquele sentimento de infância que o Renascimento começou a produzir? Talvez exigindo, no espaço escolar e na sala de aula, que as crianças tenham respostas para as perguntas que ela mesma faz à professora; que seja autônoma; que tenha desejo permanente de aprender e de se informar; que opine sobre tudo; que seja sintonizada com mudanças; que tenha sempre iniciativas; que formule hipóteses e teorias sobre as coisas; que seja independente para pensar e agir; que tenha senso de autodisciplina; que controle suas emoções; que participe solidariamente no grupo de trabalho? (CORAZZA, 1996, p. 225).
} 


\section{Referências}

ALVES, Érica Valeria. Um estudo exploratório das relações entre memória, desempenho e os procedimentos utilizados na solução de problemas matemáticos. 2005. 181f. Tese (Doutorado em Educação) - Faculdade de Educação. Universidade de Estadual de Campinas. Campinas.

AQUINO, Julio Groppa. Pedagogização do pedagógico: sobre o jogo do expert no governamento docente. Educação, Porto Alegre, v. 36, n. 2, maio/ago. 2013.

BECKER, Fernando. "O que é Construtivismo?". In: ALVES, Maria Leila; DURAN, Marilia Claret Geraes; BORJA, Amélia de; TOLEDO, Cleusa de; MATTOS, Meire Graça. (Org.). Construtivismo em revista. 2. ed. São Paulo: FDE, (série Ideias, n. 20), 1994, p. 87-93.

BORTOLI, Bruno de. Neurociência na Revista Nova Escola. 2016. 142f. Dissertação (Mestrado em Educação) - Centro de Ciências Humanas, Letras e Artes. Universidade Estadual de Maringá. Maringá.

BRASIL. Ministério da Educação. Secretaria de Educação Fundamental. Parâmetros Curriculares Nacionais: terceiro e quarto ciclos do Ensino Fundamental - Matemática. Brasília: MEC/SEF, 1998.

CORAZZA, Sandra Mara. Construtivismo: evolução ou modismo? Educação \& Realidade, Porto Alegre, v. 21, n. 2, jul./dez. 1996.

DUARTE, Claudia Glavam. A "realidade" nas tramas discursivas da Educação Matemática escolar. 2009. 191f. Tese (Doutorado em Educação) - Área de Ciências Humanas. Universidade do Vale do Rio dos Sinos. São Leopoldo.

FERRAZ, Juliana Schlatter de Lima. A memória na aprendizagem matemática. 2014. 80f. Dissertação (Mestrado em Ensino de Ciências Exatas) - Centro de Ciências Exatas e Tecnologia. Universidade Federal de São Carlos. São Carlos.

FOUCAULT, Michel. A arqueologia do saber. Tradução de Luiz Felipe Baeta Neves. 7. ed. Rio de Janeiro: Forense Universitária, 2008.

FOUCAULT, Michel. Microfísica do poder. Tradução de Roberto Machado. Rio de Janeiro: Edições Graal, 2011.

MIGUEL, Antonio; VILELA, Denise Silva. Práticas escolares de mobilização de cultura matemática. Caderno Cedes, Campinas, v. 28, n. 74, p. 97-120, jan./abr. 2008.

OLIVEIRA, Cláudio José de. Políticas educacionais e discursos sobre a Matemática escolar: um estudo a partir da Revista Nova Escola. 2006. 211f. Tese (Doutorado em Educação) - Área de Ciências Humanas. Universidade do Vale do Rio dos Sinos. São Leopoldo.

PEDROSO, Leda Aparecida. A Revista Nova Escola: política educacional na "Nova República". 1999. 277f. Tese (Doutorado em Educação) — Faculdade de Educação. Universidade Estadual de Campinas. Campinas.

ROSA, Fernanda da Silva. Revista Nova Escola e Neurociência: uma discussão sobre dispositivos biopolíticos. 2017. 99f. Dissertação (Mestrado em Educação) - Departamento de Ciências, 
Humanidades e Educação. Universidade de Santa Cruz do Sul. Santa Cruz do Sul.

ROSE, Nikolas. Inventando nossos eus. In: SILVA, Tomaz Tadeu da. (Org.). Nunca fomos humanos: nos rastros do sujeito. Belo Horizonte: Autêntica, 2001, p. 137-204.

SARTORI, Alice Stephanie Tapia. As práticas de memorização no ensino de Matemática: reconfigurações nos discursos da Revista Nova Escola. 2019. 251f. Tese (Doutorado em Educação Científica e Tecnológica) - Centro de Ciências da Educação. Universidade Federal de Santa Catarina. Florianópolis.

SILVA, Divino José; VAZ, Alexandre Fernandez. A emergência do sujeito cerebral e suas implicações para a Educação. Childhood \& Philosophy, Rio de Janeiro, v. 12, n. 24, p. 211-230, maio/ago. 2016.

SILVA, Tomaz Tadeu da. As pedagogias psi e o governo do eu nos regimes neoliberais. In: SILVA, Tomaz Tadeu da (Org.). Liberdades reguladas: as pedagogias construtivistas e outras formas de governo do eu. Petrópolis: Vozes, 1998, p. 7-13.

VIEIRA, Martha Lourenço. Construtivismo: a prática de uma metáfora-forma/conteúdo do construtivismo em Nova Escola. 1985. 75f. Dissertação (Mestrado em Educação) — Faculdade de Educação. Universidade Federal de Minas Gerais. Belo Horizonte. 